\title{
AVALIAÇÃO DE RISCO DE DESASTRES NA BACIA HIDROGRÁFICA DO RIO PURUS (BRASIL) COM BASE EM ÍNDICES COMPOSTOS
}

\author{
DISASTER RISK ASSESSMENT IN PURUS RIVER BASIN (BRAZIL) \\ BASED ON COMPOSITE INDEXES
}

\section{EVALUACIÓN DE RIESGOS DE DESASTRES EN LA CUENCA DEL RIO PURUS (BRASIL) EN BASE A INDICES COMPUESTOS}

\section{Denise Marini Pereira}

Mestre em Geografia pelo Universidade Federal do Pará. Rua Augusto Corrêa S/N, Setor Profissional Guamá, Belém - PA, 66075-900, Brasil.

Email:de.marini@yahoo.com.br

\section{Claudio Fabian Szlafsztein}

Doutor em Geografia na Universidade Federal do Pará. Rua Augusto Corrêa S/N, Setor Profissional Guamá, Belém - PA, 66075-900, Brasil.

Email: cszlafsztein@hotmail.com

\section{Fernando Alves Araújo}

Mestre em Geografia pela Universidade Federal do Pará. Rua Augusto Corrêa S/N, Setor Profissional Guamá, Belém - PA, 66075-900, Brasil.

Email: mcsfernando@gmail.com

\section{RESUMO}

Nos últimos anos, a bacia hidrográfica do rio Purus tem registrado um número crescente de situações de desastres associados a precipitações. Este trabalho avalia o risco de (re) incidência destes eventos para auxiliar no planejamento e gestão do território amazônico utilizando índices compostos de ameaças e vulnerabilidade em ambiente GIS. Os índices compostos pontuam, classificam e combinam quatro variáveis independentes associadas com o histórico de desastres entre 1971 e 2012, características morfológicas, de uso do solo e susceptibilidade a focos de calor. Os resultados apresentados em dois mapas relacionados com intenso incremento e redução precipitações, representando as subbacias das áreas do alto, médio e baixo curso da bacia. As zonas de alto e moderado risco correspondem às áreas mais antropizadas. A metodologia e resultados apresentados constituem-se importante ferramenta para refletir aspectos intrínsecos à prevenção e redução de risco de desastres em outras bacias Amazônicas.

Palavras-Chave: Desastres Naturais; Ameaças; Vulnerabilidade; Amazônia. 


\begin{abstract}
In recent years, the Purus River Basin recorded a growing number of disasters situations associated with rainfall. This paper assesses the risk of (re)incidence of these events to assist in the planning and management of the Amazon territory using indexes of hazards and vulnerability in a GIS environment. Composite indexes score, classified, and combine four independent variables associated with the history of disaster (19712012), morphology, land use and heat sources characteristics. The results are presented in two maps related to rainfall intense increases and reductions, using as subunits the high, medium and low areas of the basin. The areas of high and moderate risk correspond to more anthropised areas of the basin. The methodology and results are an important tool for reflection of intrinsic prevention and disaster risk reduction in other Amazon basins.
\end{abstract}

Keywords: Natural Disasters; Hazards; Vulnerability; Amazon.

\title{
RESUMEN
}

En los últimos años, la cuenca del rio Purus ha registrado un número creciente de situaciones de desastres asociadas a precipitaciones. Este trabajo evalúa el riesgo de (re)incidencia de estos eventos para auxiliar en la planificación y gestión del territorio amazónico utilizando índices de amenazas y vulnerabilidad en un ambiente GIS. Los índices compuestos valorizan, clasifican, y combinan quatro variables independientes asociadas con el histórico de desastres (1971 a 2012), características morfológicas, uso del suelo y focos de calor. los resultados son presentados en dois mapas relacionados con intensos incrementos e reducciones de precipitaciones representando as sub-cuencas de las áreas del alto, médio e Baixo curso de la cuenca. Las zonas de riesgo alto y moderado corresponden a las áreas mas antropizadas de la cuenca. La metodología y resultados constituyen una importante herramienta para la reflexión de aspectos intrínsecos a la prevención y reducción de riesgos de desastres en otras cuencas Amazónicas.

Palabras clave: Desastres Naturales; Amenazas; Vulnerabilidad; Amazonia.

\section{INTRODUÇÃO}

Na região Amazônica do Brasil, os desastres mais freqüentes associam-se ao intenso incremento e redução das precipitações (EM-DATA, 2013, CEPED/UFSC, 2012). Dentre as suas bacias hidrográficas, a bacia do rio Purus destaca-se em anos recentes não apenas pelos recordes fluviométricos, mas também pelo registro crescente de situações de calamidade pública (MARENGO et al.,2012; SENA et al., 2012). Em 2005 e 2010, o déficit hídrico do rio Purus e de seus afluentes repercutiram negativamente na segurança hídrica e alimentar de muitos municípios, e favoreceram a propagação descontrolada de incêndios em grandes áreas florestadas e de vegetação rasteira, elevando a concentração de fumaça na atmosfera a ponto de afetar diretamente a saúde de milhares de pessoas e interferir na 
regularidade do transporte aéreo (BROWN e PANTOJA, 2005; MARENGO, et al., 2011; DUARTE, 2011). Em 2009 e 2012, os rios da Amazônia atingiram os valores máximos dos níveis fluviométricos considerando os registros iniciados em 1903, e desalojaram mais de 15.000 famílias nos municípios amazonenses situados próximos ao rio Purus, sendo necessário o envio de ajuda humanitária para estas populações (CCST/INPE e MOHC, 2011; AMAZONAS, 2012a).

A magnitude dos impactos de desastres naturais varia conforme as características dos fenômenos naturais extremos, a vulnerabilidade da população afetada e a capacidade da sociedade em antever o evento, lidar com, resistir e se recuperar dos efeitos provocados (VILLAGRÁN, 2002; BRASIL, 2007; WESTEN, 2012). Além disso, na Região Amazônica tais impactos podem ser agravados, direta ou indiretamente, por atividades antrópicas associadas com o desmatamento e as mudanças da paisagem (DAVIDSON et al., 2012).

Diante dos cenários de aumento na freqüência e intensidade de fenômenos naturais extremos (MARENGO, 2006; CCST/INPE e MOHC, 2011; DAVIDSON et al., 2012) e do histórico de vulnerabilidade das populações amazônicas aos desastres (DUARTE, 2011; RAVENA et al., 2011; SANT'ANNA, 2012; SOUZA Jr. et al., 2012; SENA et al., 2012), este trabalho caracterizou e espacializou as ameaças naturais (local e freqüência de ocorrência) e as vulnerabilidades ambientais (suscetibilidade dos espaços físiconaturais aos fenômenos extremos) e sociais (suscetibilidade dos espaços antropizados aos fenômenos extremos) utilizando índices compostos. Os índices compostos pontuam, classificam e combinam quatro variáveis independentes associadas com o histórico de desastres entre 1971 e 2012, características morfológicas, de uso do solo e susceptibilidade a focos de calor. A partir do cruzamento de dados e análise integrada, foram identificados os principais padrões, mecanismos e fatores condicionantes da paisagem aos desastres naturais na bacia do rio Purus.

\section{ÁREA DE ESTUDO}

A bacia hidrográfica do rio Purus se situa na porção sul-ocidental amazônica. Esta bacia é a quarta maior em extensão $\left(370.000 \mathrm{~km}^{2}\right)$ dentre as sete bacias tributárias da margem direita do rio Amazonas, e abrange territórios no Peru, Bolívia e Brasil (Figura 1). Sua área aproximada em território brasileiro corresponde a $354.000 \mathrm{Km}^{2}$ distribuídos em 32 municípios nos estados do Acre, Amazonas e Rondônia (ANA, 2011). 
Figura 1. Localização da bacia hidrográfica transfronteiriça do rio Purus.

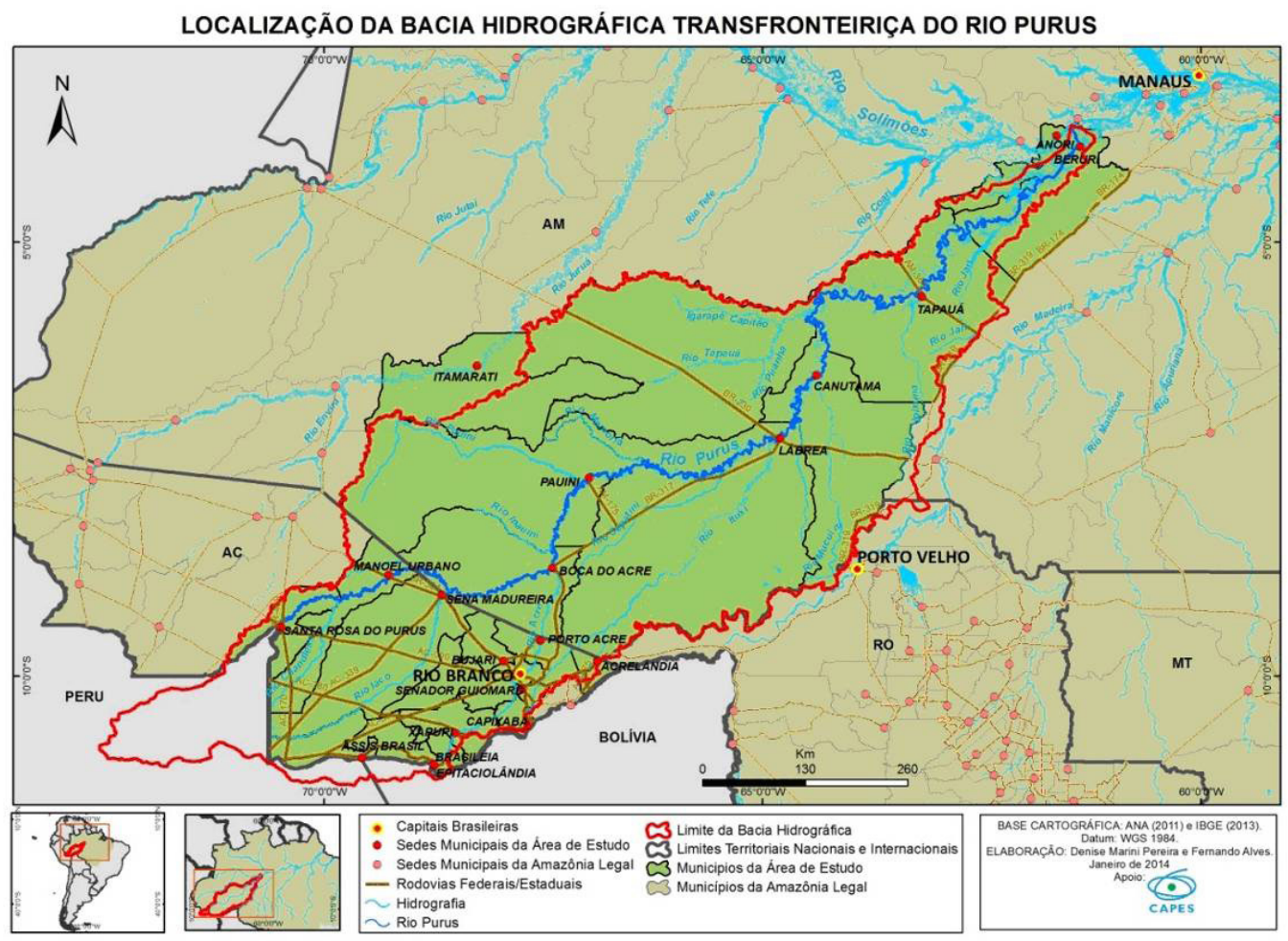

Com uma população total de 668.236 habitantes e densidade média de 4,5 hab. $/ \mathrm{km}^{2}$ (IBGE, 2010), os adensamentos populacionais da bacia do rio Purus se concentram ao longo das margens dos rios, consequência do histórico de organização espacial associado ao ritmo fluvial, do extrativismo florestal, e da agropecuária (ACRE, 2010b; RAVENA et al., 2011; AMAZONAS, 2012b). As áreas de maior concentração populacional situam-se entre o alto e médio curso da bacia, onde se desenvolvem a exploração madeireira e atividades comerciais. No baixo curso predomina uma dinâmica econômica ainda mais diretamente atrelada ao rio (ex. pesca e plantios sazonais em áreas de várzea) e concentra-se a maior parte das 23 Unidades de Conservação e 39 Terras Indígenas existentes na bacia (SOUZA Jr et al., 2012; MMA, 2013; INCRA, 2013).

\section{PROCEDIMENTOS METODOLÓGICOS}

A probabilidade dos fenômenos naturais extremos ameaçarem ou não áreas específicas da bacia do rio Purus foi estimada a partir do levantamento de registros de desastres de 150 documentos estaduais e municipais, entre 1971 a 2012, pertencentes ao banco de dados da Secretária Nacional de Defesa Civil (Quadro 1) (SEDEC, 2013). 
Os dados dos registros de desastres foram sistematizados e tabulados segundo a tipologia de eventos desastrosos de Castro (2003) e CEPED/UFSC (2012), em função de estarem associados ao incremento e à redução da precipitação, e classificados em quatro classes pelo método "Quebras Naturais" no software ArcGis 9.3. De acordo com Szlafsztein (2015), as áreas que historicamente são mais acometidas por desastres são consideradas como as de maior probabilidade de serem ameaçadas por fenômenos naturais extremos. A cada grau de ameaça foi atribuído um valor numérico (Quadro 2).

Quadro 1 - Documentos estaduais e municipais utilizados para a identificação e quantificação histórica das áreas ameaçadas por fenômenos naturais extremos na bacia do rio Purus.

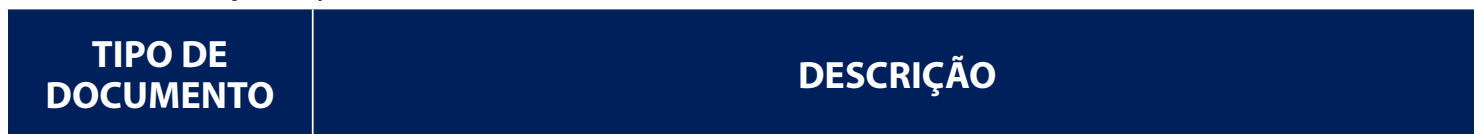

Relatório de

Documento oficial de registro de desastre emitido por prefeituras do Brasil

Danos até a década de 1990, sendo posteriormente substituído pelo AVADAN e NOPRED.

Documento oficial de registro de desastre emitido por prefeituras posterior a década de 1990. Tem por finalidade caracterizar com precisão os desastres,

Formulário de avaliar os danos humanos, materiais e ambientais e informar os prejuízos

Avaliação de econômicos e socais decorrentes dos desastres. Deve ser preenchido

Danos (AVADAN) por equipe habilitada num prazo máximo de cento e vinte horas após a ocorrência do desastre e encaminhado aos órgãos estaduais e federais de coordenação e articulação da Secretaria Nacional de Defesa Civil.

\begin{tabular}{|c|c|}
\hline $\begin{array}{l}\text { Formulário de } \\
\text { Notificação } \\
\text { Preliminar de } \\
\text { Danos (NOPRED) }\end{array}$ & $\begin{array}{l}\text { Documento que tem por finalidade alertar e encaminhar oficialmente } \\
\text { informações preliminares sobre a ocorrência de um desastre. Deve ser } \\
\text { preenchido por equipe habilitada no prazo máximo de doze horas após a } \\
\text { ocorrência de um desastre e encaminhado aos órgãos estaduais e federais } \\
\text { de coordenação e articulação da Secretaria Nacional de Defesa Civil. }\end{array}$ \\
\hline $\begin{array}{l}\text { Decreto de } \\
\text { Situação de } \\
\text { Emergência ou } \\
\text { de Calamidade } \\
\quad \text { Pública }\end{array}$ & $\begin{array}{l}\text { Declaração oficial do Governador Estadual ou do Prefeito Municipal que } \\
\text { identifica a ocorrência de desastre natural, humano ou misto, em uma } \\
\text { determinada área. Tem por finalidade alterar processos de governo e de } \\
\text { ordem jurídica no território considerado, durante o menor prazo possível } \\
\text { para restabelecer a situação de normalidade. Documento gerado após a } \\
\text { emissão do NOPRED ou AVADAN. }\end{array}$ \\
\hline Portaria & $\begin{array}{l}\text { Documento de homologação e divulgação dos Decretos Estaduais e/ou } \\
\text { Municipais de Situação de Emergência ou de Calamidade Pública emitido } \\
\text { pelo Ministério da Integração Nacional. }\end{array}$ \\
\hline Outros & Tabelas e ofícios municipais. \\
\hline
\end{tabular}

Fonte: Adaptado de SEDEC, 2013. 
Quadro 2. Classificação dos registros desastres naturais associados ao intenso Incremento e Redução das Precipitações na bacia do rio Purus.

\begin{tabular}{|c|c|c|c|c|}
\hline $\begin{array}{c}\text { Número de Registros de } \\
\text { Desastres }\end{array}$ & \multicolumn{4}{|c|}{ Ameaça } \\
\hline Classes & Tipo & Sigla & Grau & $\begin{array}{l}\text { Atributo } \\
\text { Numérico }\end{array}$ \\
\hline 0 & \multirow{4}{*}{$\begin{array}{l}\text { Associados ao } \\
\text { Incremento das } \\
\text { Precipitações }\end{array}$} & \multirow{4}{*}{ AlP } & Inexistente & 0 \\
\hline 1 a 3 & & & Baixo & 1 \\
\hline 4 a 6 & & & Moderado & 2 \\
\hline 7 a 16 & & & Alto & 3 \\
\hline 0 & \multirow{4}{*}{$\begin{array}{c}\text { Associados à } \\
\text { Intensa Redução das } \\
\text { Precipitações }\end{array}$} & \multirow{4}{*}{ ARP } & Inexistente & 0 \\
\hline 1 & & & Baixo & 1 \\
\hline 2 & & & Moderado & 2 \\
\hline 3 a 4 & & & Alto & 3 \\
\hline
\end{tabular}

Elaboração: Os autores.

Neste trabalho a análise da vulnerabilidade foi abordada considerando as suas dimensões ambientais e sociais.

A avaliação da Vulnerabilidade Ambiental aos Desastres Associados ao Incremento das Precipitações (VAIP) desenvolveu-se em duas etapas. A primeira corresponde à caracterização das unidades geomorfológicas da bacia naturalmente propensas a inundação. Levantamentos bibliográficos referentes à geotectônica regional permitiram compreender os condicionantes naturais de sua formação e analisar os principais padrões espaciais dessa e das demais unidades geomorfológicas (planaltos e depressões) da área de estudo. Complementariamente, tais unidades foram espacializadas no software ArcGis 9.3. a partir de dados vetoriais (shapefile) com geometria de polígonos na escala 1:250.000 obtidos junto ao Sistema de Proteção da Amazônia (SIPAM, 2013).

A segunda etapa consistiu na identificação e a quantificação da VAIP utilizando-se de dados de morfometria (diferenças altimétricas do relevo) da bacia do rio Purus obtidos a partir de um Modelo Digital de Elevação (MDE), com resolução espacial de 90 metros, construído a partir de imagens de radar da missão SRTM (Shuttle Radar Topography Mission), oriundas do site Global Land Cover Facility (GLCF, 2013). As variações do relevo foram agrupadas, a partir do método "Quebras Naturais", em sete classes, sendo o grau de vulnerabilidade alto para os intervalos altimétricos de menor valor e baixo para as 
maiores altitudes. Cada grau de vulnerabilidade recebeu um valor numérico para compor o cálculo de risco de desastres no desenvolvimento da álgebra de mapas (Quadro 3). Em conjunto ao MDE classificado, realizou-se apenas a sobreposição da Planície Amazônica, unidade geomorfológica de maior propensão às enchentes e inundações, para averiguar sua extensão em correspondência com as áreas de menor cota altimétrica.

Quadro 3. Classificação da Vulnerabilidade Ambiental aos desastres Associados ao Incremento das Precipitações na bacia do rio Purus.

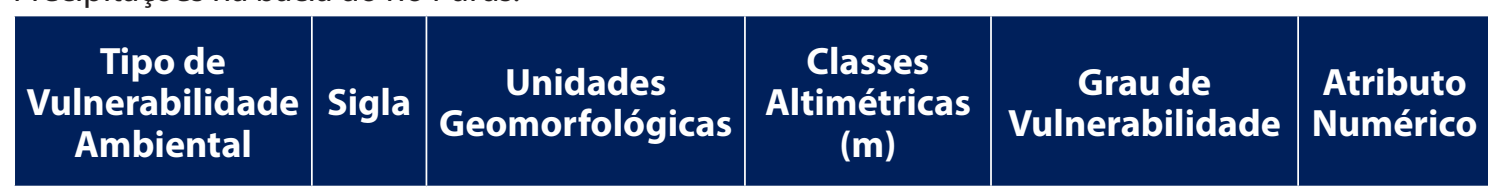

\begin{tabular}{|c|c|c|c|c|c|}
\hline \multirow{7}{*}{$\begin{array}{l}\text { Associada ao } \\
\text { Incremento das } \\
\text { Precipitações }\end{array}$} & & \multirow{3}{*}{$\begin{array}{l}\text { Planícies e } \\
\text { Depressões }\end{array}$} & 0 a 80 & \multirow{3}{*}{ Alta } & \multirow{3}{*}{3} \\
\hline & \multirow{6}{*}{ VAIP } & & 81 a 123 & & \\
\hline & & & 124 a 168 & & \\
\hline & & Depressões & 169 а 219 & Moderada & 2 \\
\hline & & \multirow{3}{*}{$\begin{array}{l}\text { Depressões e } \\
\text { Planaltos }\end{array}$} & 220 a 280 & \multirow{3}{*}{ Baixa } & \multirow{3}{*}{1} \\
\hline & & & 281 a 362 & & \\
\hline & & & 363 a 545 & & \\
\hline
\end{tabular}

Elaboração: Os autores.

$\mathrm{O}$ aumento do número de eventos de queimadas e incêndios florestais na região (BROWN et al., 2011; ACRE, 2013 e VASCONCELOS et al., 2013) foi associado à Vulnerabilidade Ambiental Associada à Intensa Redução das Precipitações (VARP). Neste sentido, dados de focos de calor, disponíveis no "Portal de Monitoramento de Queimadas e Incêndios" do Instituto Nacional de Pesquisas Espaciais (INPE, 2014) em formato vetorial com geometria de pontos referente aos anos de 2005 a 2012, são utilizados. Os focos de calor identificam temperaturas de superfície acima de $47^{\circ} \mathrm{C}$, captados por sensores termais espaciais (resolução espacial superior a $1 \mathrm{Km}^{2}$ ).

A estimativa do adensamento e padrão de distribuição dos focos de calor foi realizada no software ArcGis 9.3 pelo algoritmo Kernel Density, que mediante interpolação, distribuiu os dados em nove classes de densidade com intervalos iguais. Estes dados foram reclassificados pelo método das "Quebras Naturais" e agrupados em graus de vulnerabilidade em relação de conformidade direta com a concentração de focos de calor por $\mathrm{Km}^{2}$. Valores numéricos foram atribuídos a cada grau de vulnerabilidade para compor o cálculo do risco de desastre a ser realizado por álgebra de mapas (Quadro 4). 
Quadro 4. Classificação da Vulnerabilidade Ambiental aos desastres Associados à intensa Redução das Precipitações na bacia do rio Purus.

\begin{tabular}{|c|c|c|c|c|}
\hline $\begin{array}{c}\text { Tipo de } \\
\text { Vulnerabilidade } \\
\text { Ambiental }\end{array}$ & Sigla & $\begin{array}{l}\text { Classes de Focos } \\
\text { de Calor } / \mathrm{Km}^{2}\end{array}$ & $\begin{array}{c}\text { Grau de } \\
\text { Vulnerabilidade }\end{array}$ & $\begin{array}{l}\text { Atributo } \\
\text { Numérico }\end{array}$ \\
\hline \multirow{8}{*}{$\begin{array}{c}\text { Associada à Intensa Redução } \\
\text { das Precipitações }\end{array}$} & \multirow{8}{*}{ VARP } & $<0,62$ & \multirow{2}{*}{ Baixa } & \multirow{2}{*}{1} \\
\hline & & $0,62-1,25$ & & \\
\hline & & $1,26-1,87$ & \multirow{2}{*}{ Moderada } & \multirow{2}{*}{2} \\
\hline & & $1,88-2,50$ & & \\
\hline & & $2,51-3,12$ & \multirow{4}{*}{ Alta } & \multirow{4}{*}{3} \\
\hline & & $3,13-3,75$ & & \\
\hline & & $3,76-4,37$ & & \\
\hline & & $4,38-5,62$ & & \\
\hline
\end{tabular}

Elaboração: Os autores.

A análise e o mapeamento da Vulnerabilidade Social (VS) utilizaram dados de desmatamento (supressão total da vegetação florestal ou corte raso), por tais espaços antropizados serem sensíveis às variações climáticas extremas. Segundo Kobyama et al. (2006) e Davidson et al. (2012), nestas áreas há maior ocorrência de danos ambientais (perdas de biomassa e do equilíbrio ecossistêmico) e socioeconômicos (redução da disponibilidade de água para consumo humano, danos a infraestruturas, produtividade agrícola e econômica). Os dados referentes às áreas desmatadas, obtidos no site do Projeto PRODES (INPE, 2012), são disponibilizados para o ano de 1997 e o período de 2000 a 2012 em mosaicos estaduais de formato vetorial shapefile com geometria de polígonos. A informação do centro geométrico de cada polígono foi convertida em ponto pela ferramenta Feature To Point do ArcGis 9.3. A ferramenta Kernel Density, do mesmo programa, interpolou os dados e os classificou em nove classes de densidade com intervalos iguais. Estas foram agrupadas em Baixa, Moderada e Alta vulnerabilidade considerando a concentração de números de polígonos do desmatamento por $\mathrm{Km}^{2}$, sendo-lhes atribuído respectivamente um valor numérico para a realização do cálculo de risco de desastres através da álgebra de mapas (Quadro 5). 
Quadro 5. Classificação da Vulnerabilidade Social aos desastres associados ao incremento e intensa redução das precipitações na bacia do rio Purus.

\begin{tabular}{|c|c|c|c|c|}
\hline $\begin{array}{c}\text { Tipo de } \\
\text { Vulnerabilidade Social }\end{array}$ & Sigla & $\begin{array}{l}\text { Classes de Polígonos de } \\
\text { Desmatamento } / \mathrm{Km}^{2}\end{array}$ & $\begin{array}{c}\text { Grau de } \\
\text { Vulnerabilidade }\end{array}$ & $\begin{array}{l}\text { Atributo } \\
\text { Numérico }\end{array}$ \\
\hline \multirow{8}{*}{$\begin{array}{l}\text { Associada ao Incremento } \\
\text { e Intensa Redução das } \\
\text { Precipitações Hídricas }\end{array}$} & \multirow{8}{*}{ VS } & $<0,87$ & \multirow{2}{*}{ Baixa } & \multirow{2}{*}{1} \\
\hline & & $0,87-1,29$ & & \\
\hline & & $1,30-1,73$ & \multirow{2}{*}{ Moderada } & \multirow{2}{*}{2} \\
\hline & & $1,74-2,16$ & & \\
\hline & & $2,17-2,60$ & \multirow{4}{*}{ Alta } & \multirow{4}{*}{3} \\
\hline & & $2,61-3,04$ & & \\
\hline & & $3,05-3,47$ & & \\
\hline & & $3,38-3,92$ & & \\
\hline
\end{tabular}

Elaboração: Os autores.

Para complementar as análises, realizou-se a identificação e o cálculo percentual dos tipos de uso e ocupação das áreas desmatadas no software ArcGis 9.3. a partir de dados do projeto TerraClass (INPE, 2010), mosaicos estaduais de formato vetorial shapefile com geometria de polígonos.

O mapeamento e cálculo dos riscos de desastres naturais na bacia do rio Purus foi realizado através de álgebra dos mapas com os dados referentes às ameaças e vulnerabilidades. Previamente, a ferramenta "Union" do software ArcGis 9.3. transformou as intersecções em novas feições, de modo a manter os atributos de todas as variáveis envolvidas. Em seguida, foram realizadas as seguintes operações com a ferramenta "Field Caculator", do mesmo programa, para gerar os valores componentes dos mapas de avaliação de Riscos (Tabela 1):

a. Risco de desastres associados ao incremento das precipitações (RIP)

$$
\text { RIP }=\text { AIP x }(\text { VAIP + VS) }
$$

b. Risco de desastres associados à intensa redução das precipitações (RRP)

$$
\mathrm{RRP}=\mathrm{ARP} x(\mathrm{VARP}+\mathrm{VS})
$$

Onde:

AIP $=$ Atributo das Ameaças a desastres associados ao Incremento das Precipitações;

VAIP = Atributo de Vulnerabilidade Ambiental a desastres associados ao Incremento das Precipitações;

VS = Atributo de Vulnerabilidade Social a desastres naturais;

$\mathrm{ARP}=$ Atributo das Ameaças a desastres associados à intensa Redução das Precipitações;

VARP = Atributo de Vulnerabilidade Ambiental a desastres associados à intensa Redução das Precipitações. 
Tabela 1. Valores numéricos obtidos pela operação de multiplicação dos graus de ameaça e vulnerabilidade aos desastres naturais associados ao intenso incremento e redução das precipitações na bacia do rio Purus.

\begin{tabular}{c|cccccc}
\hline RISCO DE DESASTRE NATURAL & \multicolumn{6}{|c}{ Vulnerabilidade (Ambiental + Social) } \\
\hline Ameaça & 1 & 2 & 3 & 4 & 5 & 6 \\
\hline 0 & 0 & 0 & 0 & 0 & 0 & 0 \\
\hline 1 & 1 & 2 & 3 & 4 & 5 & 6 \\
\hline 2 & 2 & 4 & 6 & 8 & 10 & 12 \\
\hline 3 & 3 & 6 & 9 & 12 & 15 & 18 \\
\hline
\end{tabular}

Elaboração: Os autores.

Os resultados destas operações foram agrupados em quatro classes, considerando graus de risco de desastre natural inexistente, baixo, moderado e alto. Atributos numéricos lhes foram auferidas para simplificação da representação das classes de risco (Quadro 6).

Quadro 6. Classificação dos riscos aos desastres naturais segundo os valores numéricos obtidos pela operação de multiplicação dos graus de ameaças e vulnerabilidades aos desastres naturais associados ao intenso incremento e redução das precipitações na bacia do rio Purus.

\begin{tabular}{ccc}
\multicolumn{3}{c}{ Risco de Desastre Natural } \\
\hline Classes & Grau & Atributo Numérico \\
\hline 0 & Inexistente & 0 \\
\hline $1-4$ & Baixo & 1 \\
\hline $5-9$ & Moderado & 2 \\
\hline $10-18$ & Alto & 3 \\
\hline
\end{tabular}

Elaboração: Os autores.

\section{RESULTADOS E DISCUSSÕES}

\section{FENÔMENOS EXTREMOS AMEAÇADORES DE DESASTRES NATURAIS}

Os municípios de Boca de Acre (AM) e Rio Branco (AC) configuram-se como áreas altamente ameaçadas por apresentarem, respectivamente, 8 e 16 registros de desastres associados ao incremento das precipitações (AIP). Com exceção dos municípios de Senador Guiomard, Capixaba, Bujari e Acrelândia, situados a sudeste da bacia do rio Purus no estado do Acre, os 15 municípios restantes foram classificados como de baixa e moderada ameaça (Figura 2). 
Figura 2. Ameaça de desastres naturais associados ao incremento das precipitações nos municípios da bacia do rio Purus (1971 a 2012).

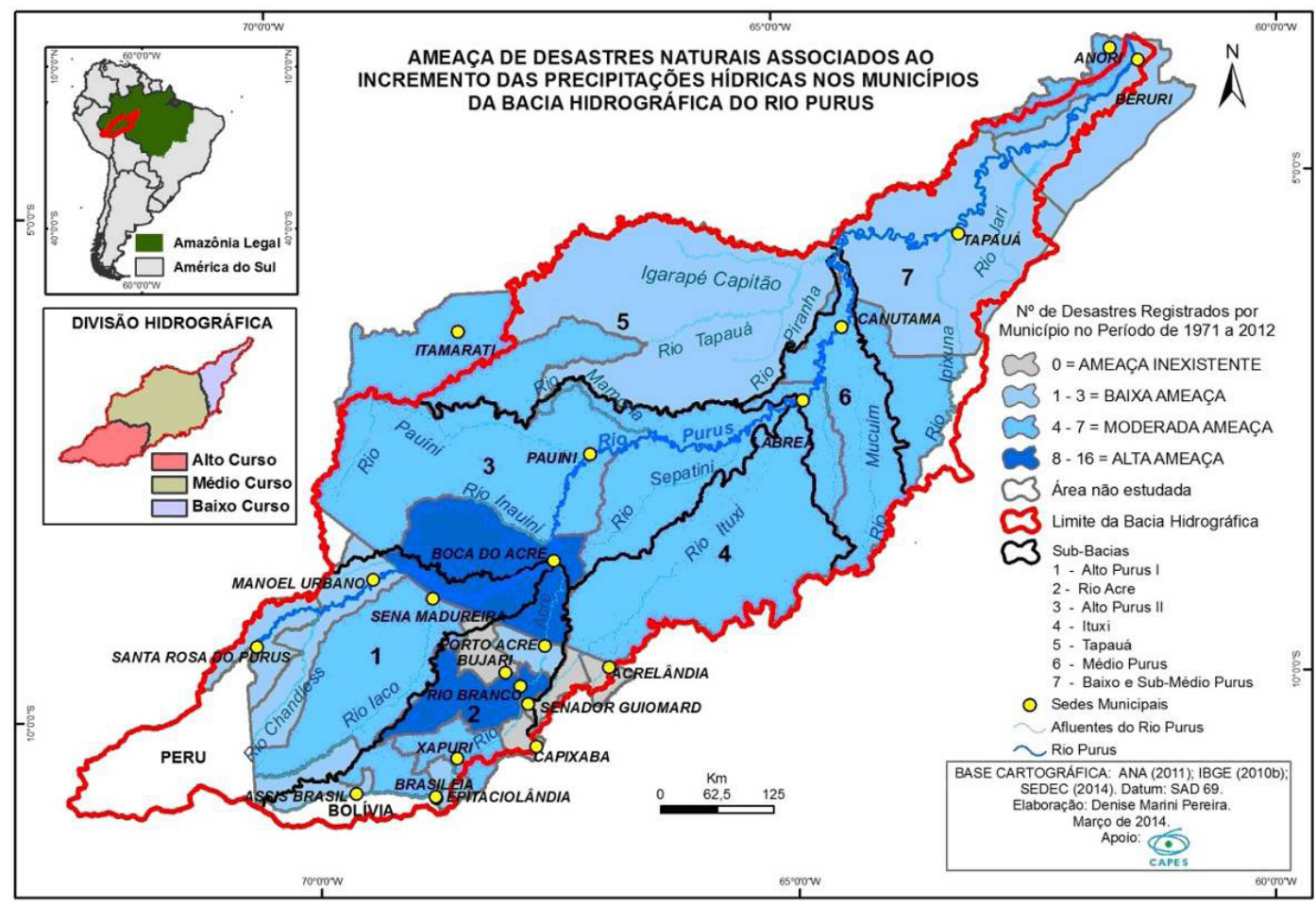

Em relação às AIRP, o grau moderado se concentra majoritariamente na região do médio e baixo curso da bacia (Figura 3). Canutama (AM) e novamente Boca do Acre $(\mathrm{AM})$ se destacam como áreas de alta ameaça e quase todos os municípios da bacia já foram afetados por tais fenômenos extremos, há exceção apenas de Santa Rosa do Purus e Manoel Urbano no estado do Acre. 
Figura 3. Ameaça de desastres naturais associados a intensa redução das precipitações nos municípios da bacia do rio Purus (1971 a 2012).

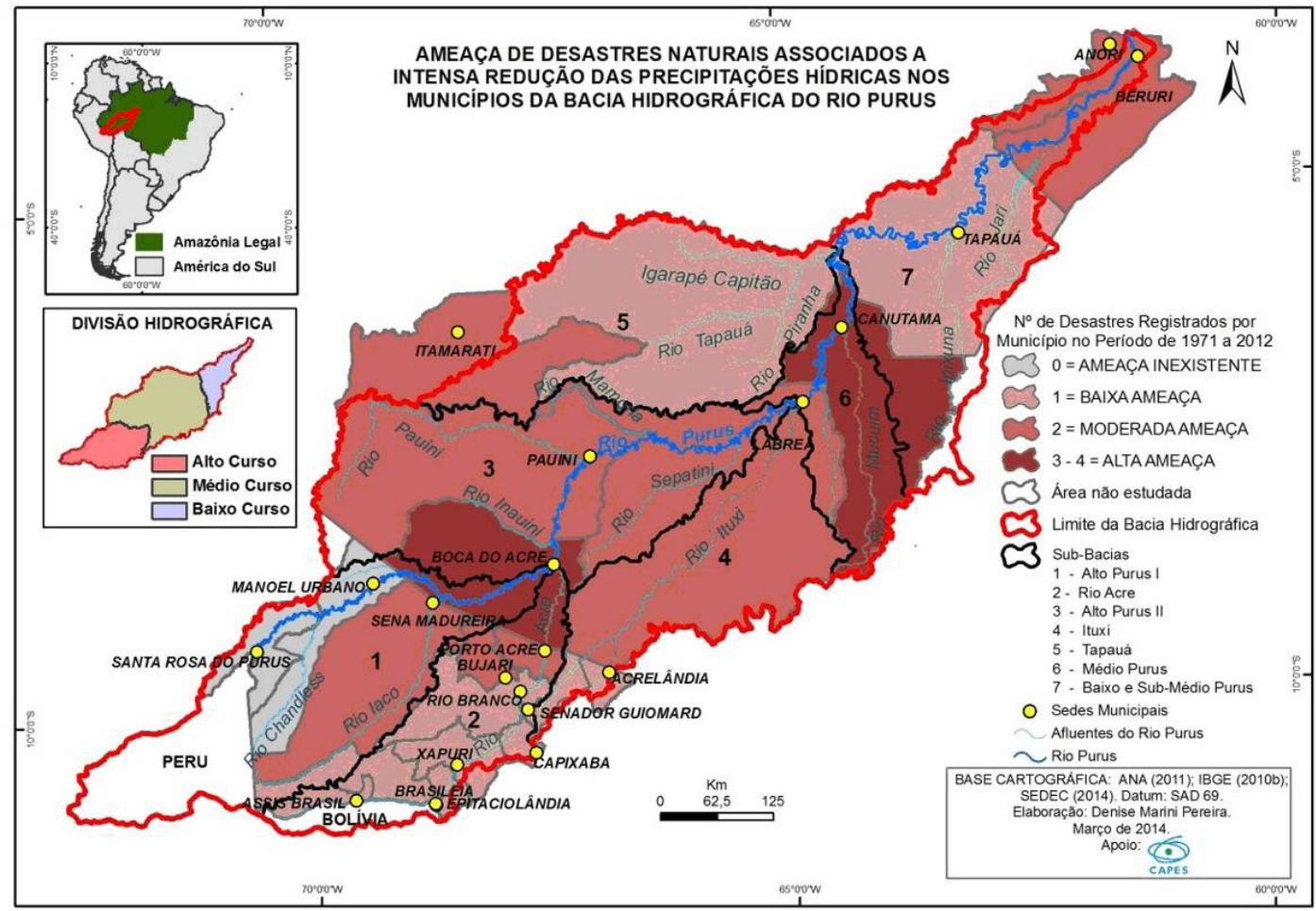

De 1971 a 2012, 24 anos registram desastres naturais na bacia do rio Purus, estando o maior número associados ao incremento das precipitações hídricas em 2009 (10 enchentes e 3 erosões fluviais) e 2012 ( 11 enchentes e inundações e 6 alagamentos). 2005 ( 11 incêndios florestais e 8 secas) e 2010 ( 7 estiagens) são anos de referência de maior número de registro de desastres associados a intensa redução das precipitações hídricas (SEDEC, 2014).

\section{VULNERABILIDADES AOS DESASTRES NATURAIS}

- Vulnerabilidade Ambiental

As áreas ambientalmente vulneráveis aos desastres associados ao incremento das precipitações estão relacionadas, em sua maioria, as características físicas do relevo, que em grande escala associam-se na Amazônia às transgressões e regressões marinhas e aos movimentos tectônicos (Costa et al., 2001; ACRE, 2010a; CPRM, 2006). Os ciclos de movimentos distensivos, compressivos e transformantes sob a ação de fatores climáticos pretéritos e atuais resultaram na configuração de doze unidades geomorfológicas (Figura 4). Devido a intensos processos de dissecação fluvial e pediplanação, tais unidades são caracterizadas como superfícies aplainadas com pouca capacidade de absorção das 
águas (solos hidromórficos e de origem sedimentar). Assim, diante de ameaças naturais relacionadas ao incremento das precipitações, tais características favorecem a ocorrência de eventos como inundações ou alagamentos em grande parte da bacia.

A Planície Amazônica destaca-se como a área de maior propensão aos desastres relacionados ao incremento das precipitações por ser associada às áreas topograficamente mais baixas da bacia e por sua própria morfogênese ser decorrente de inundações fluviais periódicas.

Figura 4. Unidades geomorfológicas da bacia hidrográfica transfronteiriça do rio Purus.

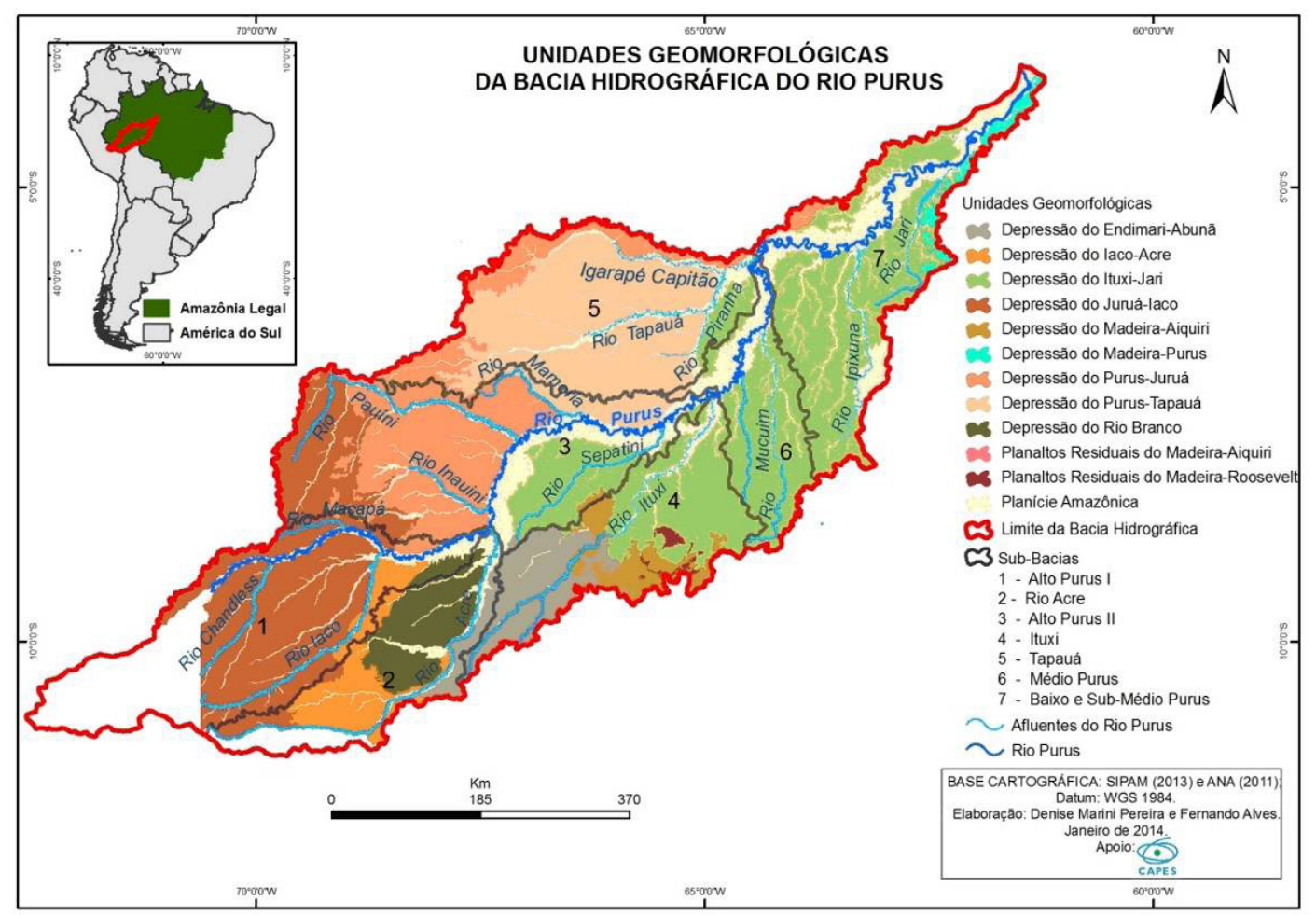

Mais de 60\% da bacia do rio Purus (cerca de $230.000 \mathrm{~km}^{2}$ ) encontra-se em situação de alta VAIP, pelo predomínio de estruturas geomorfológicas decorrentes de intenso processo de dissecação fluvial e pediplanação com terrenos baixos e planos no baixo e médio curso da bacia. As sub-bacias Tapauá, Médio Purus e Baixo e Sub-Médio Purus, destacam-se pela predominância das Depressões Ituxi-Jari e Purus-Tapauá com os menores valores altimétricos (0 a $123 \mathrm{~m}$ ) e maior extensão da Planície Amazônica ao longo dos afluentes do rio Purus. Nas sub-bacias Alto Purus II, particularmente com um dos trechos com maior largura da Planície Amazônica, e Ituxi abrangem as três classes altimétricas de alta vulnerabilidade. Com exceção da parte norte, nas sub-bacias Alto Purus I e Rio Acre, 
predominam a baixa VAIP pelos níveis altimétricos (entre 220 a $545 \mathrm{~m}$ ) das Depressões Juruá-Iaco, Iaco-Acre e do Rio Branco (Figura 5 e Quadro 7).

Figura 5. Vulnerabilidade ambiental a desastres associados ao incremento das precipitações hídricas na bacia hidrográfica do rio Purus.

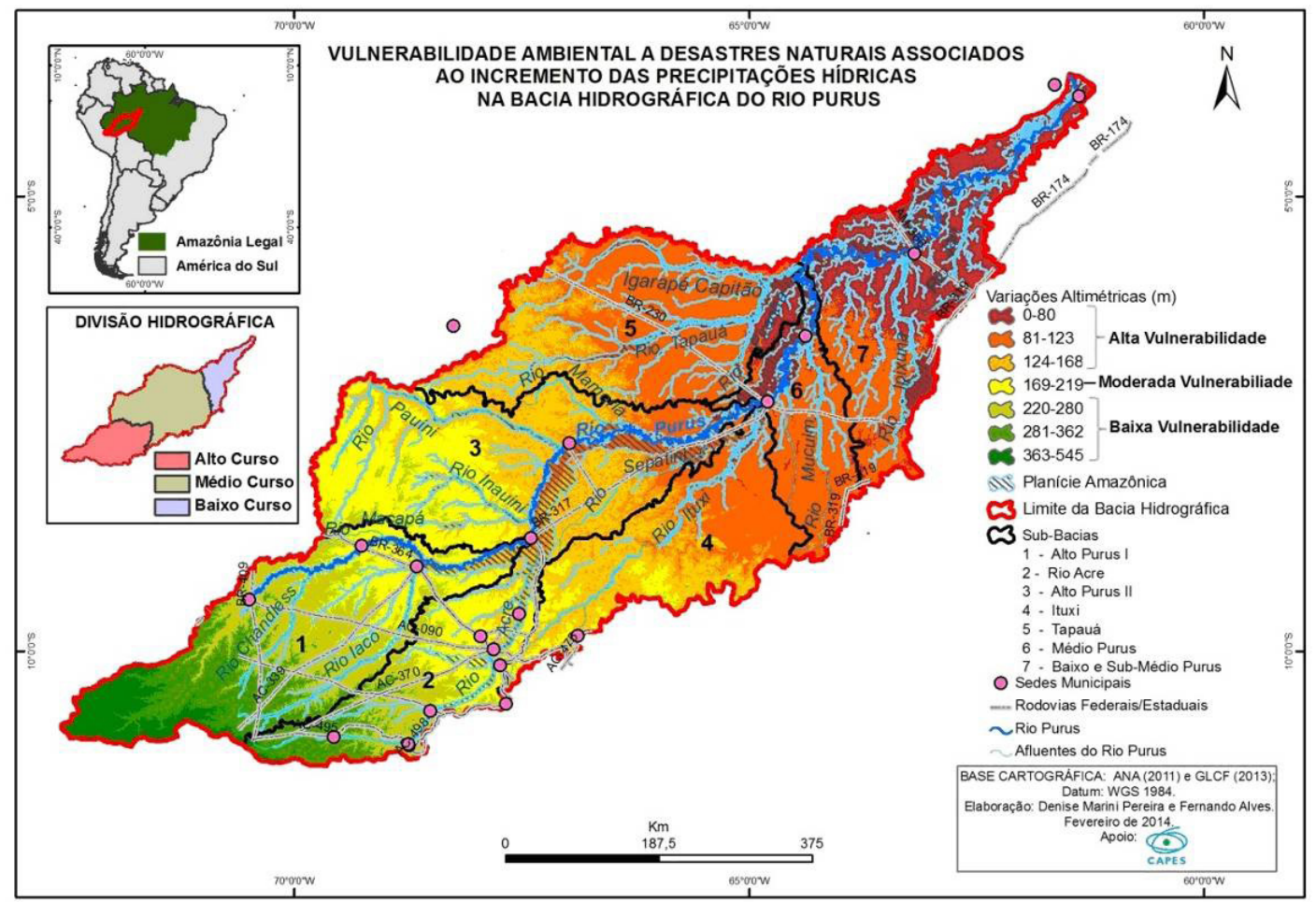

Quadro 7. Vulnerabilidade Ambiental a desastres naturais associados ao Incremento das Precipitações (VAIP) na bacia do rio Purus. Fonte dos dados de altimetria: GLCF, 2013.

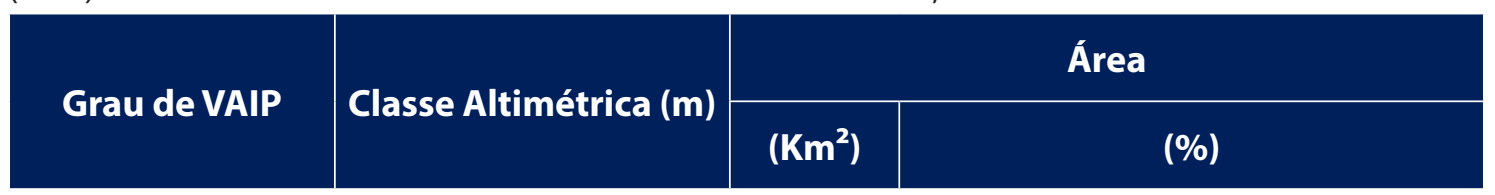

\begin{tabular}{cccc}
\multirow{2}{*}{ Alta } & $0-80$ & 65.876 & 18,4 \\
\cline { 2 - 4 } & $81-123$ & 95.367 & 26,63 \\
\cline { 2 - 4 } Moderada & $124-168$ & 72.722 & 20,31 \\
\hline \multirow{2}{*}{ Baixa } & $169-219$ & 59.553 & 16,63 \\
\cline { 2 - 4 } & $220-280$ & 33.745 & 9,42 \\
\cline { 2 - 4 } & $281-362$ & 22.106 & 6,17 \\
\hline
\end{tabular}

Elaboração: Os autores. 
Os focos de calor na bacia do rio Purus concentram-se nas proximidades das sedes municipais e rodovias federais e estaduais. As áreas com alta VARP correspondem a 7\% da área total $\left(25.163 \mathrm{~km}^{2}\right.$ ), e se agrupam na região sudeste da bacia (sub-bacias Rio Acre, Ituxi e Alto Purus II, e extremo centro-sul da sub-bacia Médio Purus). Áreas sem ou com escassos adensamentos de sedes municipais e rodovias apresentam uma baixa VARP, a sudoeste da sub-bacia Alto Purus I, no extremo sul da sub-bacia do Rio Acre, e na totalidade das sub-bacias Tapauá e Baixo e Sub-Médio Purus (Quadro 8 e Figura 6).

Figura 6. Vulnerabilidade ambiental a desastres naturais associados à intensa redução das precipitações na bacia hidrográfica do rio Purus.

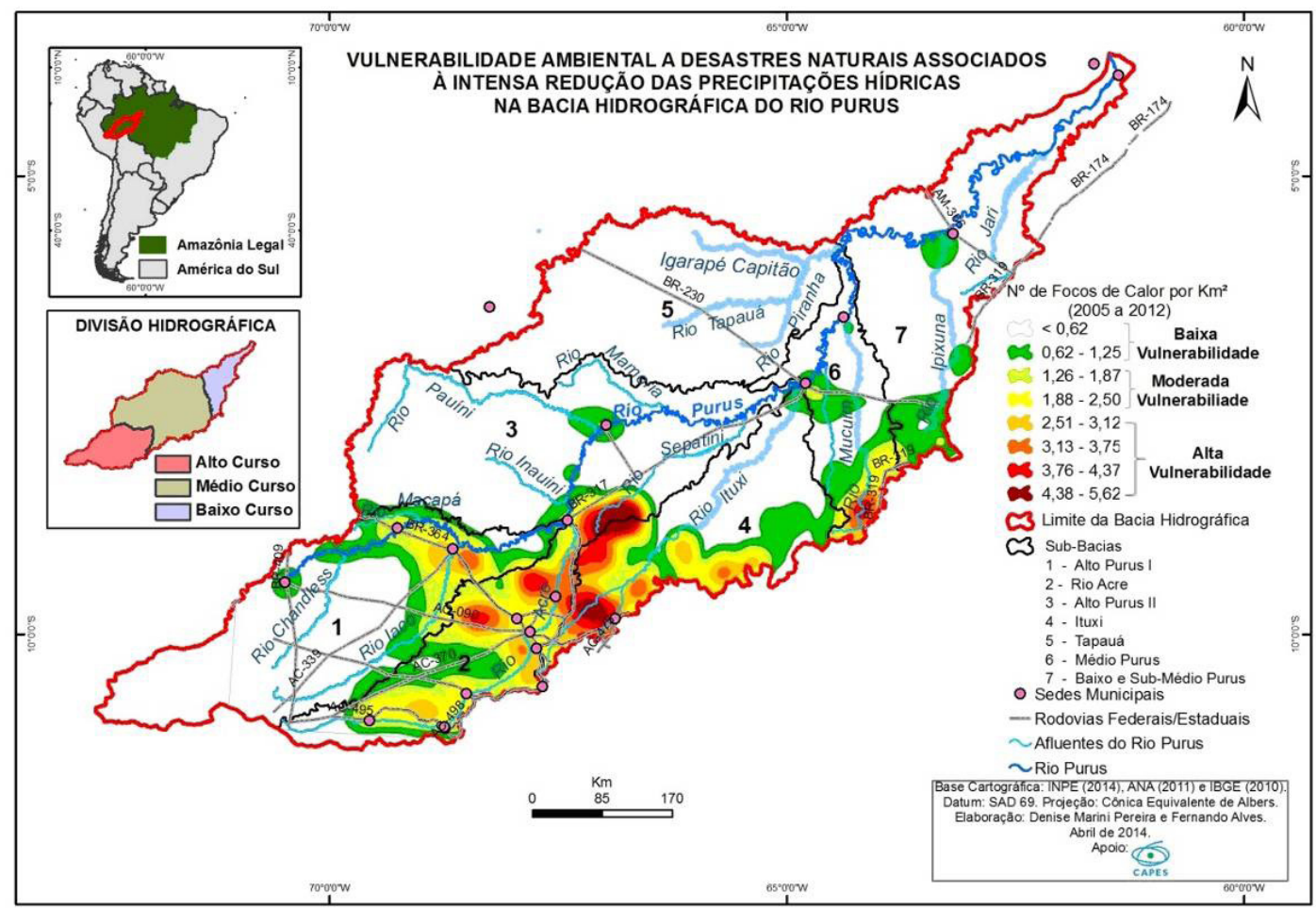


Quadro 8. Vulnerabilidade Ambiental a desastres naturais associados à intensa Redução das Precipitações (VARP) na bacia do rio Purus. Fonte dos dados de focos de calor: INPE, 2014.

\begin{tabular}{|c|c|c|c|}
\hline \multirow{2}{*}{ Grau de VARP } & \multirow{2}{*}{ Focos de Calor/ Km² } & \multicolumn{2}{|c|}{ Área } \\
\hline & & $\left(\mathrm{Km}^{2}\right)$ & $(\%)$ \\
\hline \multirow{2}{*}{ Baixa } & $<0,62$ & 254.322 & 70,74 \\
\hline & $0,62-1,25$ & 44.592 & 12,4 \\
\hline \multirow{2}{*}{ Moderada } & $1,26-1,87$ & 18.664 & 5,19 \\
\hline & $1,88-2,50$ & 16.774 & 4,67 \\
\hline \multirow{4}{*}{ Alta } & $2,51-3,12$ & 11.427 & 3,18 \\
\hline & $3,13-3,75$ & 7.113 & 1,98 \\
\hline & $3,76-4,37$ & 4.135 & 1,15 \\
\hline & $4,38-5,62$ & 2.488 & 0,69 \\
\hline
\end{tabular}

Elaboração: Os autores.

\section{- Vulnerabilidade Social}

As áreas de maior adensamento de desmatamento representam maior grau de Vulnerabilidade Social (VS) e situam-se no alto curso da bacia, principalmente na subbacia do Rio Acre, e parcialmente ao norte da sub-bacia Alto Purus I, onde há maior concentração de rodovias federais e estaduais e sedes municipais. No extremo sul da subbacia Ituxi, próximo à sede municipal de Acrelândia e a rodovia AC-475, localiza-se a maior área de desflorestamento de toda a bacia. As sub-bacias Alto Purus II e Médio Purus se assemelham em relação à distribuição de áreas com baixa e moderada vulnerabilidade também próximas a sedes municipais e rodovias. As sub-bacias Tapauá e Baixo e Sub-Médio Purus são as únicas que possuem exclusivamente áreas de baixa vulnerabilidade (Figura 7). 
Figura 7. Vulnerabilidade Social a desastres naturais na bacia hidrográfica do rio Purus.

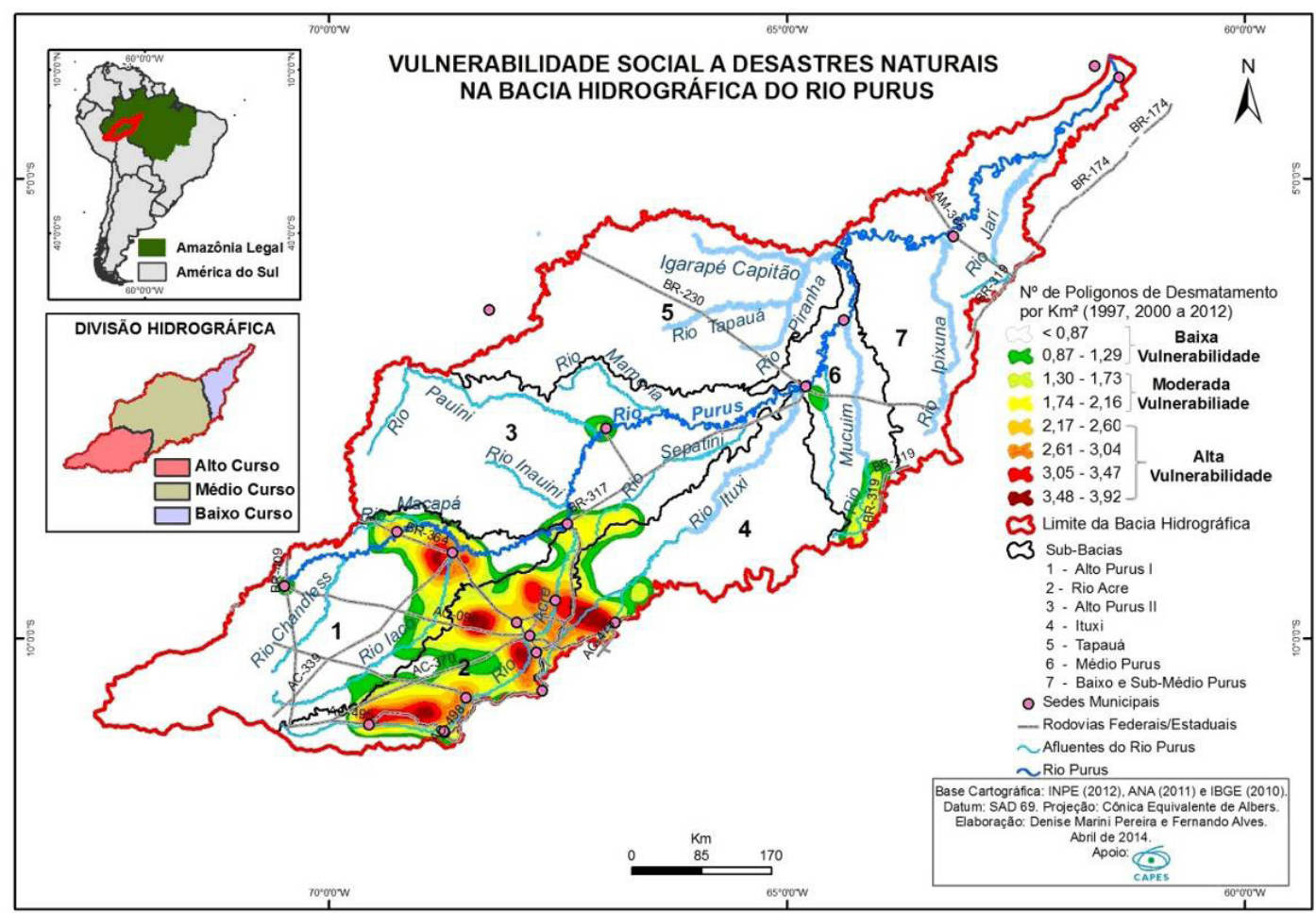

Menos de 10\% da bacia está em situação de alta e moderada VS (Quadro 9), possivelmente justificado pela grande extensão de áreas de floresta preservada e intervenções antrópicas restritas a pequenas porções de seu território (ex. pasto limpo 3,36\%; vegetação secundária 1,71\% e mosaico de ocupações 0,13\%) (INPE 2010).

Quadro 9. Vulnerabilidade Social (VS) a desastres naturais na bacia do rio Purus. Fonte dos dados de desmatamento: INPE, 2012.

\begin{tabular}{|c|c|c|c|}
\hline \multirow{2}{*}{$\begin{array}{c}\text { Grau de } \\
\text { VS }\end{array}$} & \multirow{2}{*}{$\begin{array}{c}\text { Desmatamento/ } \\
\mathrm{Km}^{2}\end{array}$} & \multicolumn{2}{|c|}{ Área } \\
\hline & & $\left(\mathrm{Km}^{2}\right)$ & (\%) \\
\hline \multirow{2}{*}{ Baixa } & $<0,87$ & 310.802 & 88,09 \\
\hline & $0,87-1,29$ & 13.305 & 3,77 \\
\hline \multirow{2}{*}{ Moderada } & $1,30-1,73$ & 8.647 & 2,45 \\
\hline & $1,74-2,16$ & 6.671 & 1,89 \\
\hline \multirow{4}{*}{ Alta } & $2,17-2,60$ & 6.786 & 1,92 \\
\hline & $2,61-3,04$ & 3.974 & 1,12 \\
\hline & $3,05-3,47$ & 1.913 & 0,54 \\
\hline & $3,38-3,92$ & 744 & 0,21 \\
\hline
\end{tabular}

Elaboração: Os autores. 


\section{RISCO DE DESASTRES NATURAIS}

A dimensão espacial da combinação dos dados de ameaças e vulnerabilidades é estratégica para a avaliação das áreas em situação de risco, possibilitando projeções e simulações de diferentes cenários com potencial de uso para alerta precoce de desastres (HOGAN e MARANDOLA Jr., 2007; WESTEN, 2012). Na bacia do rio Purus, a configuração das áreas de risco segundo a tipologia dos eventos desastrosos se apresenta pelas figuras 8 e 9

Figura 8. Risco de Desastres Naturais associados ao incremento das precipitações hídricas na bacia hidrográfica do rio Purus.

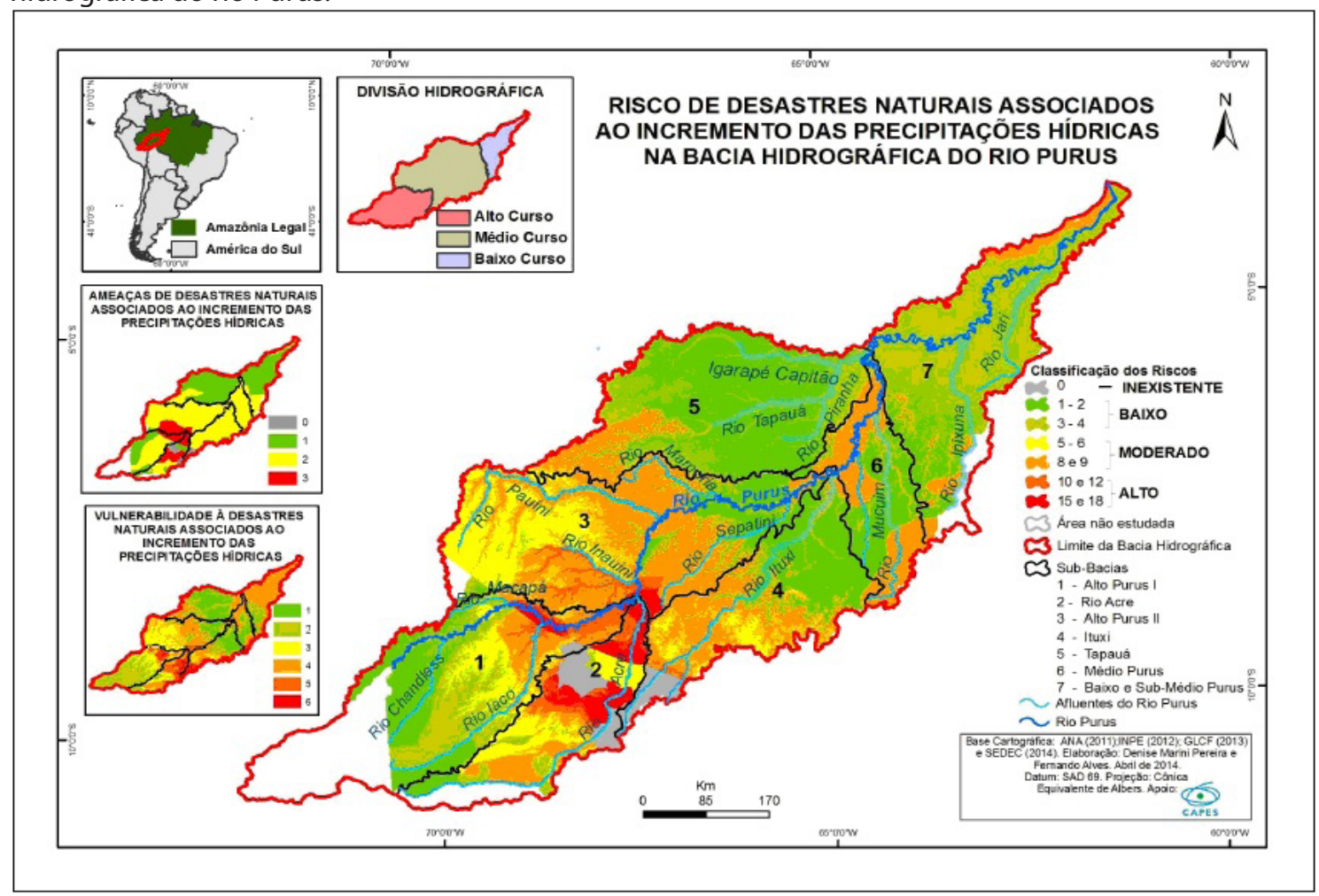

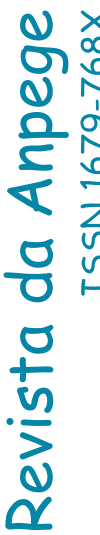

a 
Figura 9. Risco de desastres naturais associados à intensa redução das precipitações na bacia hidrográfica do rio Purus.

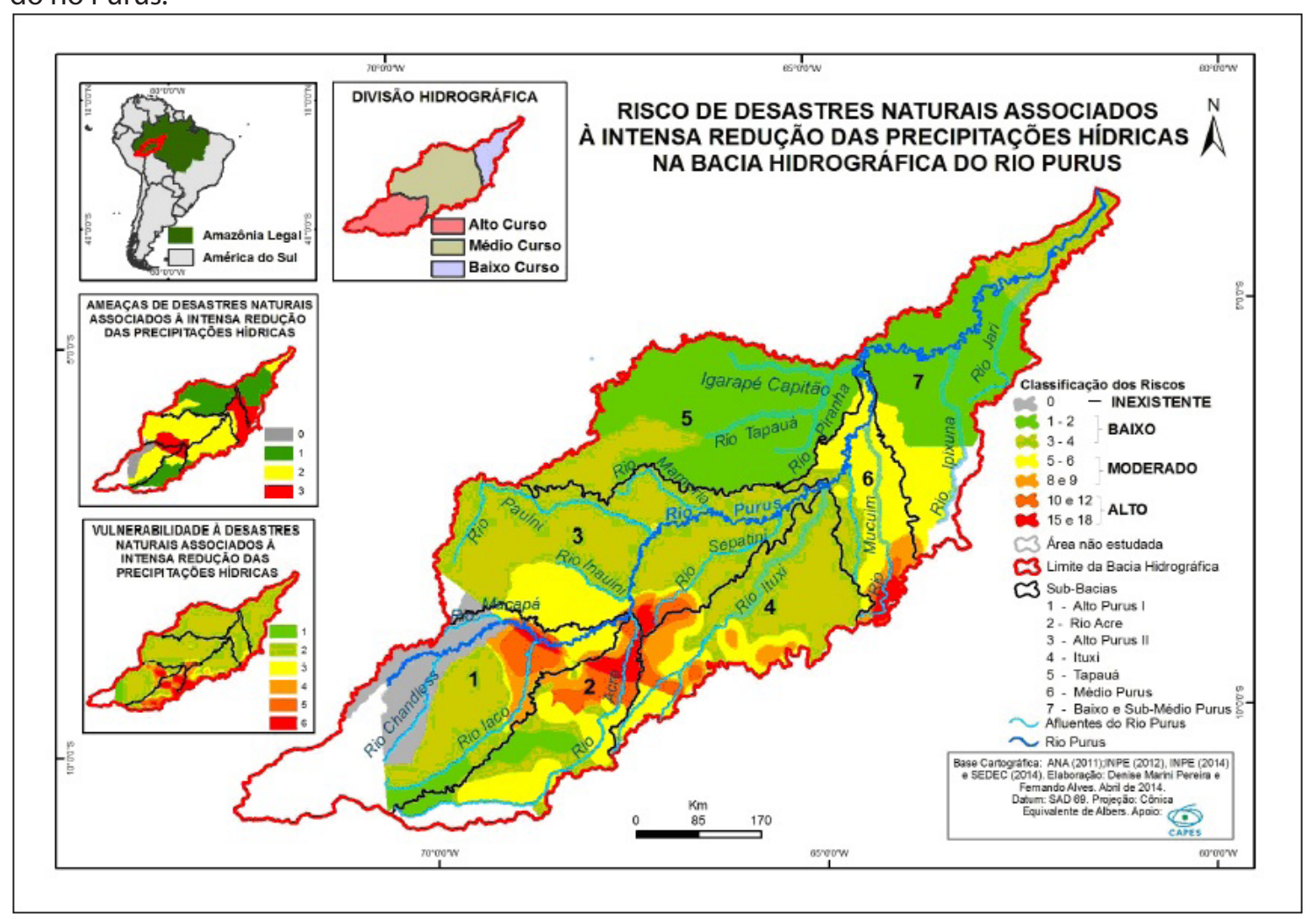

Pelas ameaças e vulnerabilidades serem baixas e moderadas na maior parte da área de estudo, as áreas de RIP e RRP são predominantemente baixos (respectivamente 45\% e $60 \%$ do total). As áreas de alto RIP (6\%) e RRP (5\%) se concentram na confluência do rio Purus com os rios Inauini, Acre e Iaco, os espaços mais antropizados da bacia. O risco inexistente aos dois tipos de desastres ( $\mathrm{RIP}=14 \%$ e $\mathrm{RRP}=17 \%)$ também se concentraram no alto curso da bacia, porém em localidades que não apresentaram dados de ameaças.

\section{CONCLUSÕES}

Através da integração dos dados de ameaças e vulnerabilidades avaliou-se a dimensão dos riscos por cada tipo de desastre natural. Semelhanças foram apresentadas na distribuição dos riscos, sendo o alto risco correspondente às áreas mais antropizadas da bacia; o risco inexistente em localidades pertencentes ao alto curso; e as áreas menos ameaçadas vulneráveis aos desastres naturais foram equivalentes as de baixo risco na maior parte da bacia. 
Com os resultados obtidos ao longo desta pesquisa se observou alguns fatores limitantes para a abordagem do risco em totalidade integrada às suas dimensões. Em relação às ameaças, uma vez que estas se constituem em fenômenos decorrentes de variações anômalas na dinâmica dos sistemas naturais, sejam eles atmosféricos, terrestres, espaciais ou relativos à biocenose, estes variam em magnitude, intensidade e periodicidade, podendo ser cíclicos ou eventuais, não afetando de forma uniforme regiões e populações. Sendo assim, a compreensão dos motivos que levam algumas áreas serem mais ameaçadas do que outras exige estudos em menor escala de detalhe que reúnam variáveis referentes às condições sociais, econômicas e ambientais específicas da localização geográfica.

Neste sentido, e de modo relevante, a inexistência de dados públicos sobre todas ou a maioria das populações tradicionais das UC e TI que pudessem ser correlacionados com dados socioeconômicos das demais populações da bacia, inviabilizou o conhecimento das particularidades das dinâmicas territoriais dessas áreas no âmbito da vulnerabilidade social aos desastres. Tais dados poderiam apontar o potencial efetivo dessas áreas na redução do risco de desastres e auxiliar na valoração das mesmas no planejamento e gestão dos riscos de desastres. Cabe citar que, a articulação entre as diversas dimensões do risco e da vulnerabilidade (cultural, institucional, socioeconômico e entre outros) numa escala espacial e temporal adequada ainda se constitui em grande desafio a ser trabalhado na área de estudo, principalmente nas UC e TI, que exigem análises em escala de maior detalhe. Para a obtenção de informações mais precisas e escala de maior detalhe quanto a VS, sugere-se para trabalhos futuros a utilização dos dados históricos do projeto TerraClass, que trás uma classificação dos polígonos do desmatamento, permitindo atribuir com maior acurácia o grau de vulnerabilidade das áreas desflorestadas.

Em suma, a metodologia utilizada desenvolveu o tema multidisciplinar de riscos a partir dos principais aspectos físico-naturais e antrópicos das paisagens que são determinantes para a ocorrência de desastres naturais, e passíveis de serem correlacionados independentes dos limites político-administrativos dos territórios. Conclui-se que, a utilização da bacia hidrográfica como unidade de estudo se mostrou eficaz para a estimativa de risco de desastres diante de fenômenos hidroclimáticos extremos tendo propiciado uma abordagem holística dos fatores e processos envolvidos. As discussões e resultados aqui apresentados objetivaram agregar conhecimento e servir de ferramenta à compreensão deste cenário amazônico deveras extenso e complexo do território nacional. Por fim, a avaliação de risco aos desastres naturais por bacias hidrográficas comprovou ser importante ferramenta para o planejamento e ordenamento do território por refletir aspectos intrínsecos da paisagem com potencial de prevenção e redução de risco de desastres. 


\section{REFERÊNCIAS}

1. ACRE (ESTADO). Lei $\mathbf{n}^{\circ} \mathbf{2 . 3 0 8}$, de 22 de outubro de 2010a. Cria o Sistema Estadual de Incentivos a Serviços Ambientais - SISA, o Programa de Incentivos por Serviços Ambientais - ISA Carbono e demais Programas de Serviços Ambientais e Produtos Ecossistêmicos do Estado do Acre e dá outras providências. Disponível em: <http://www.aleac.net/sites/default/ files/Lei2308_1.pdf>. Acesso em: mar. 2014.

2. ACRE (ESTADO). Recursos naturais: geologia, geomorfologia e solos do Acre. ZEE/AC, fase II, escala 1:250.000/ Programa Estadual de Zoneamento Ecológico -Econômico do Acre. Secretaria de Estado de Meio Ambiente: Rio Branco. 2010b. 100p.

3. ACRE (ESTADO). Guia para o uso da terra acreana com sabedoria: Resumo educativo do Zoneamento Ecológico-Econômico do Acre - fase II (escala 1:250.000). Secretaria de Estado de Meio Ambiente: Rio Branco, 2010c. 152p.

4. ACRE (ESTADO). Plano integrado de prevenção, controle e combate às queimadas e aos incêndios florestais do estado do Acre. Secretaria de Estado de Meio Ambiente: Rio Branco,

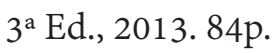

5. AMAZONAS (ESTADO). Lei Complementar $n^{\circ}$ 53, de 05 de junho de 2007. Regulamenta o inciso V do artigo 230 e o $\$ 1^{\circ}$ do artigo 231 da Constituição Estadual, institui o Sistema Estadual de Unidades de Conservação - SEUC, dispondo sobre infrações e penalidades e estabelecendo outras providências. Disponível em: <http://legislador.aleam.gov.br/LegisladorWEB/ LegisladorWEB.ASP?WCI=LeiConsulta\&ID=201\&nrLeiDE=53\&inEspecieLei=2ঊ>. Acesso em: mar. 2014.

6. AMAZONAS (ESTADO). Mais dois municípios do Amazonas decretam situação de emergência. Subcomando de Ações de Defesa Civil do Amazonas: Manaus, 2012a. Disponível em: <http://www.defesacivil.am.gov.br/noticia/mais-dois-municipios-do-amazonas-decretamsituacao-de-emergencia/>. Acesso em: dez. 2012.

7. AMAZONAS (ESTADO). Zoneamento Ecológico-Econômico da Sub-Região do Purus. Secretaria de Estado de Meio Ambiente e Desenvolvimento Sustentável: Manaus, 2012b. 452p.

8. ANA. Plano estratégico de recursos hídricos da bacia Amazônica: afluentes da margem direita. Agência Nacional de Águas: Brasília, 2011. Disponível em: <http://www2.ana.gov.br/ Paginas/imprensa/noticias.aspx>. Acesso em: mar. 2013.

9. BRASIL. Congresso Nacional. Decreto $\mathbf{n}^{\circ} \mathbf{6 . 0 4 0}$, de 7 de fevereiro de 2007. Institui a Política Nacional de Desenvolvimento Sustentável dos Povos e Comunidades Tradicionais. Disponível em: <http://www.planalto.gov.br/ccivil_03/_ato2007-2010/2007/decreto/d6040.htm>. Acesso em: mar. 2014.

10. BROWN, I; Pantoja, N. Seca do rio e fogo na floresta. Página 20, Rio Branco, 2 de agosto de 2005.

11. BROWN, I; SANTOS, G; PIRES, F; COSTA, C. Brazil: Drought and Fire Response in the Amazon. World Resources Report. (Org.) Decision Making in a Change Climate. United States: World Resources Report, p. 81-83, 2011. 
12. Câmara, G; Davis, C; Monteiro, A. M. V. Geoprocessamento: teoria e aplicações. Instituto Nacional de Pesquisas Espaciais. São José dos Campos, 2001. Disponível em: $<h t t p: / / w w w$. dpi.inpe.br/gilberto/livro/>. Acesso em: abr. 2013.

13. CARDONA, O; VAN AALST, M; BIRKMANN, J; FORDHAM, M; MCGREGOR, G; PEREZ R; PULWARTY, R; SCHIPPER, E; SINH, B. Determinants of risk: exposure and vulnerability. In: Field, C; Barros, V; Stocker, T; Dahe, Q; Dokken, D; Ebi, K; Mastrandrea, M; Mac, K; Plattner, G; Allen, S; Tignor, M; Midgley, P. (eds.). Managing the risks of extreme events and disasters to advance climate change adaptation - A special report of working groups I and II of the Intergovernmental Panel on Climate Change (IPCC). New York: Cambridge University Press, p. 65-108, 2012.

14. CASTRO, A. Manual de desastres: desastres naturais. Ministério da Integração Nacional: Brasília, 2003. 182p.

15. CCST/INPE e MOHC. Riscos das mudanças climáticas no Brasil: análise conjunta BrasilReino Unido sobre os impactos das mudanças climáticas e do desmatamento na Amazônia. Centro de Ciências do Sistema Terrestre do Instituto Nacional de Pesquisas Espaciais \& Met Office Hadley Centre.:São José dos Campos, 2011. 56p.

16. CEPED/UFSC. Atlas brasileiro de desastres naturais 1991 a 2010: volume Brasil. Centro Universitário de Estudos e Pesquisas sobre Desastres da Universidade Federal de Santa Catarina: Florianópolis, 2012.94p.

17. Costa, J; Bemerguy, R; Hasui, Y; Borges, M; Tectonics and paleogeography along the Amazon river. Journal South American Earth Sciences. Volume 14. Issue 4, 335-347. 2001.

18. CPRM. Geologia e recursos minerais do estado do Amazonas. Serviço Geológico do Brasil: Manaus, 2006. 153p.

19. CPTEC/INPE e INMET. Tendência temperaturas variando de normal a acima da média em todo o Brasil. Centro de Previsão do Tempo e Estudos Climáticos do Instituto de Pesquisas Espaciais e Instituto de Meteorologia: São José dos Campos. Infoclima: Boletim de Informações Climáticas 12 (10), 2005.

20. Davidson, E; Araújo, A; Artaxo, P.; Balch, J.; Brown, I; Bustamante, M; Coe, M; Defries, R; Keller, M; Longo, M; Munger, J; Schroeder, W; Soares Filho, B; Souza Junior, C; Wofsy, S. The Amazon basin in transition. Nature. 481: 321-328. 2012.

21. DUARTE, A. As chuvas e as vazões na bacia hidrográfica do rio Acre, Amazônia Ocidental: caracterização e implicações socioeconômicas e ambientais. Amazônia: Ciência e Desenvolvimento, 6 (12): 161-183, 2011.

22. Echeverri, J. Pueblos indígenas y cambio climático: El caso de La Amazonía colombiana. Bulletin de I'Institut Français d'Études Andines, 38: 13-28, 2009.

23. EM-DAT - INTERNATIONAL DISASTER DATABASE. Center for Research on the Epidemiology of Disasters - CRED. Disponível em: <http://www.emdat.be/result-countryprofile >. Acesso em: mar. 2013. 
24. GLCF. Earth Science Data Interface - Elevation Data SRTM. Global Land Cover Facility, 2013. Disponível em: <http:// http://glcf.umd.edu/data/>. Acesso em: mai. 2013.

25. HOGAN, D; MARANDOLA JR., E. Vulnerabilidade a perigos naturais nos estudos de população e ambiente. In: HOGAN, D. (Org.). Dinâmica populacional e mudança ambiental: cenários para o desenvolvimento brasileiro. Campinas: Núcleo de Estudos de População (NEPO/UNICAMP), pp. 73-86, 2007.

26. IBGE. Informações dos municípios brasileiros - População 2010. Instituto Brasileiro de Geografia e Estatística, Brasília. 2010. Disponível em: <http://cidades.ibge.gov.br/xtras/home. php>. Acesso em: mai. 2013.

27. INCRA. Acervo da malha fundiária do Brasil - Download dos limites das Terras Indígenas. Instituto Nacional De Colonização E Reforma Agrária, 2013. Disponível em: <http:// acervofundiario.incra.gov.br/i3geo >. Acessado em: set. 2013.

28. INPE. Dados TerraClass 2010. Instituto Nacional de Pesquisas Espaciais: São José dos Campos, 2010. Disponível em: $<h t t p: / / w w w . i n p e . b r / c r a / p r o j e t o s \_p e s q u i s a s / t e r r a c l a s s 2010 . p h p>$. Acesso em: jun. 2014.

29. INPE. Projeto PRODES: Monitoramento da floresta amazônica brasileira por satélite. Instituto Nacional de Pesquisas Espaciais. São José dos Campos, 2012. Disponível em: <http://www. dpi.inpe.br/prodesdigital/prodes.php>. Acesso em: fev. 2014.

30. INPE. Portal de Monitoramento de Queimadas e Incêndios. Instituto Nacional de Pesquisas Espaciais. São José dos Campos, 2014. Disponível em: <http://www.dpi.inpe.br/proarco/ bdqueimadas/>. Acesso em: jan. 2014.

31. IPCC. Managing the risks of extreme events and disasters to advance climate change adaptation - A special report of working groups I and II of the Intergovernmental Panel on Climate Change. Intergovernmental Panel On Climate Change. New York; Cambridge University Press, 582p. 2012.

32. MA. Ecosystems and Human Well-Being: Synthesis. Millennium Ecosystem Assessment, Washington: Island Press, 2005.

33. MARENGO, J. Mudanças climáticas e seus efeitos sobre a biodiversidade: caracterização do clima atual e definição das alterações climáticas para o território brasileiro ao longo do século XXI. Brasília: Ministério do Meio Ambiente. 212p. 2006.

34. MARENGO, J; TOMASELlA, J; ALVES, L; SOARES, W; RODRIGUEZ, D. The drought of 2010 in the context of historical droughts in the Amazon region. Geophysical Research Letters. 38: 1-5, 2011.

35. MARENGO, J; TOMASELLA, J; SOARES, W; ALVES, L; NOBRE, C. Extreme climatic events in the Amazon basin: Climatological and hydrological context of recent floods. Theoretical and Applied Climatology. 85: 73-85, 2012.

36. MMA. Download de dados geográficos das Unidades de Conservação. Ministério do Meio Ambiente: Brasília, 2013. Disponível em: <http://mapas.mma.gov.br/izgeo/datadownload. htm>. Acessado em: set. 2013. 
37. RAVENA, N; CANETE, V; SOUZA, C; CANETE, T; SOUSA, R. A política das águas na Amazônia: as especificidades da relação entre o marco legal e os usuários da bacia do rio Purus. Teoria \& Pesquisa. 20 (2): 59-80, 2011.

38. Sant'anna, F. Tensões e conflitos na governança dos recursos hídricos amazônicos transfronteiriços. GEOUSP - Espaço e Tempo, 31: 132-154, 2012.

39. SEDEC. Banco de dados e registros de desastres. Secretaria Nacional de Proteção e Defesa Civil, 2014. Disponível em: < http://s2id.mi.gov.br/>. Acesso em: dez. 2013.

40. SENA, J; FREITAS, M; BERRÊDO, D; FERNANDES, L. Evaluation of vulnerability to extreme climatic events in the Brazilian Amazonia: Methodological proposal to the Rio Acre Basin. Water Resources Management. 26: 4553-4568, 2012.

41. SOUZA JR, W; WAICHMAN, A; SINISGALli, P; ANGELIS, C; ROMEIRO, A. Rio Purus: águas, território e sociedade na Amazônia sul-ocidental. Goiânia: Libri Mundi, 282p. 2012.

42. SZLAFSZTEIN, C. Natural Disaster Management in the Brazilian Amazon: an analysis of the States of Acre, Amazonas and Pará. In: Cheval, S. (Org.). Natural Disaster. 1 ed. Zagreb: INTECH, 1-20, 2012.

43. SZLAFSZTEIN, C. Metodologia de análise e mapeamento de vulnerabilidade na Amazônia. In: Chang, M; Goés, K; Fernandes, L; Freitas, M; Rosa, L. Metodologias de estudos de vulnerabilidade à mudança do Clima. Coleção Mudanças Globais, 6: 108-125. Editora Interciência. Rio de Janeiro. 2015.

44. SZLAFSZTEIN, C; MARQUES, O; MAIA, H; FISCHENICH, P; PIVA, L. Referências metodológicas para mapeamento de riscos naturais na Amazônia: mapeando vulnerabilidades. Brasília: GTZ/MMA, 2010.

45. VASCONCELOS, S; FEARNSIDE, P; GRAÇA, P; NOGUEIRA, E; OLIVEIRA, L; FIGUEIREDO, E. Forest fires in southwestern Brazilian Amazonia: estimates of area and potential carbon emissions. Forest Ecology and Management. 291: 199-208, 2013.

46. VILLAGRAN, J. La naturaleza de los riesgos, un enfoque conceptual. In: Serie aportes para el Desarrollo Sostenible. Guatemala: Centro de Investigación y Mitigación de Desastres Naturales(CIMDEN). 2002. 53p.

47. Westen, C. Remote sensing and GIS for natural hazards assessment and disaster risk management. In: Centre for Space Science and Technology Education in Asia and the Pacific (CSSTEAP). Application of space technology for disaster risk reduction: international training course lecture notes. India: India Institute of Remote Sensing (IIRS), 307-375, 2012.

Artigo recebido em 20 de dezembro de 2015.

Aceito para publicação em 12 de junho de 2016 